Check for updates

The BMJ

Cite this as: $B M J 2022 ; 376: 0565$ http://dx.doi.org/10.1136/bmi.0565 Published: 03 March 2022

\section{Covid-19: Public vaccine funding needs "strings attached" for equitable access, say campaigners}

\author{
Elisabeth Mahase
}

Public funding given to companies for future vaccine development should have global access requirements built into agreements to avoid the inequity seen during the covid-19 pandemic, campaigners have said.

Speaking at the Westminster Health Forum on 21 February, Tahir Amin, co-founder and co-executive director of I-MAK-a US based group that campaigns for increased access to affordable drugs-highlighted that pharmaceutical companies have been given billions of dollars in public funds for vaccine development in recent years with "no strings attached."

"Given the amount of public funding that has gone into many of these vaccines, government contracts need to have better terms and provisions that allow for greater access," Amin said.

Vaccine inequity has been a major problem during the pandemic, with high income countries rolling out third or even fourth vaccine doses to their populations while many in low income countries have yet to receive a first dose. Even in 2022, after nearly 11 billion doses have been administered globally, only $13 \%$ of people in low income countries have received at least one dose as of 1 March. ${ }^{1}$

Speaking at a World Health Organization event last year, Richard Hatchett, chief executive officer of the Coalition for Epidemic Preparedness Innovations, said it was a "tragedy" that vaccine funders did not include access provisions in their funding agreements. $^{2}$

\section{Scientific racism}

Amin said he believes "scientific racism" has also played a role in the inequity, with high income countries holding on to a belief that developing countries can't manufacture vaccines. "We need to get out of that old colonial mindset that only the global north can develop vaccines and make them," he said. He added that in emergency situations like a pandemic, intellectual property rules should be "put aside," especially when public funding has driven a lot of the development.

Efforts are now being made by organisations like WHO to enable vaccine manufacturing in low income countries, with the launch of the global mRNA technology transfer hub which aims to share technology and technical knowledge with local producers in order to scale up manufacturing capacity for covid-19 vaccines. But the work is largely being done without help from major vaccine developers.

In February, WHO announced that Egypt, Kenya, Nigeria, Senegal, South Africa, and Tunisia would be the first countries involved in the mRNA hub. This came after its research partner Afrigen was able to produce small scale batches of an mRNA vaccine based on the publicly available sequence of the largely publicly funded Moderna vaccine. ${ }^{3}$

Médecins Sans Frontières (MSF) is now calling on Moderna to share its vaccine technology and knowledge with manufacturers across the world and to withdraw all patents related to mRNA vaccines in order to reduce the intellectual property barriers to biosimilar vaccine production and quickly boost global supply. ${ }^{4}$ Moderna has reported billions of dollars in profits from the covid-19 vaccine so far. ${ }^{5}$

MSF has identified over 100 manufacturers across Asia, Africa, and Latin America with the potential to manufacture mRNA vaccines. ${ }^{6}$

Moderna did not respond to The BMJ's request for a comment.

\section{Coronavirus vaccinations. https://ourworldindata.org/covid-vaccinations. \\ 2 Covid-19 global research and innovation forum. May 2021 www.who.int/teams/blueprint/covid-19/covid-19-global-research-innovation- forum. \\ 3 WHO announces first technology recipients of mRNA vaccine hub with strong support from African and European partners. https://worldhealthor- ganization.cmail20.com/t/ViewE- mail/d/01EFOCC5A78FB6832540EF23F30FED ED/OCCC24126AC59F0223B7CB3C95A53812. \\ 4 MSF welcomes WHO announcement that six African countries will receive tech needed to produce COVID mRNA vaccines. www.doctorswithoutbor- ders.org/what-we-do/news-stories/news/msf-welcomes-who-announce- ment-six-african-countries-will-receive-tech. \\ 5 Moderna posts billions profit covid-19 vaccine but won't share technology. www.doctorswithoutborders.org/what-we-do/news-stories/news/moderna- posts-billions-profit-covid-19-vaccine-wont-share-technology. \\ 6 Pharmaceutical firms across Asia, Africa and Latin America with potential to manufacture mRNA vaccines. https://msfaccess.org/pharmaceutical- firms-across-asia-africa-and-latin-america-potential-manufacture-mrna- vaccines.}

This article is made freely available for personal use in accordance with BMJ's website terms and conditions for the duration of the covid-19 pandemic or until otherwise determined by BMJ. You may download and print the article for any lawful, non-commercial purpose (including text and data mining) provided that all copyright notices and trade marks are retained. 